\title{
CHEP 2018: Preface to the Proceedings
}

\author{
Alessandra Forti $^{1}$, Latchezar Betev $^{2}$, Maarten Litmaath ${ }^{2}$, Oxana Smirnova $^{3}$, Petya \\ Vasileva $^{2}$, Vassil Vassilev ${ }^{4}$, and Peter Hristov ${ }^{2}$ \\ ${ }^{1}$ University of Manchester, Oxford Rd, Manchester M13 9PL, UK \\ ${ }^{2}$ CERN, Esplanade des Particules 1, P.O. Box, 1211 Geneva 23, Switzerland \\ ${ }^{3}$ Lund University, Box 117, 22100 Lund, Sweden \\ ${ }^{4}$ Princeton University, Princeton, NJ 08544, USA
}

\begin{abstract}
The $23^{\text {rd }}$ International Conference on Computing in High Energy and Nuclear Physics (CHEP) took place in the National Palace of Culture, Sofia, Bulgaria from $9^{\text {th }}$ to $13^{\text {th }}$ of July 2018. 575 participants joined the plenary and the eight parallel sessions dedicated to: online computing; offline computing; distributed computing; data handling; software development; machine learning and physics analysis; clouds, virtualisation and containers; networks and facilities. The conference hosted 35 plenary presentations, 323 parallel presentations and 188 posters.
\end{abstract}

\section{CHEP conference series}

The CHEP conference series was established in 1985 and ever since, CHEP has been one of the most important events in the field of computing in high energy and nuclear physics. The conference covers a broad set of topics such as online, offline and distributed computing; software development, simulation, reconstruction and analysis packages; data handling, data bases and storage solutions; clouds, virtualisation and containers; networking and facilities. It provides a discussion platform between the physicists, computing scientists and IT engineers, as well as between renowned experts and young researchers. The conference is held every 18 months and the host has been selected on "rotational" principle among locations in Europe, the Americas and Asia/Pacific. The conference focuses on the achievements, ongoing activities, plans and trends in the field. The list of past CHEP conferences is shown in Table 1.

Table 1. Past CHEP Conferences

\begin{tabular}{|c|c|c|}
\hline Name & Dates & Location \\
\hline CHEP'85 & 25-28 June 1985 & $\begin{array}{c}\text { Amsterdam, } \\
\text { Netherlands }\end{array}$ \\
\hline CHEP'87 & 2-6 February 1987 & $\begin{array}{c}\text { Asilomar, California, } \\
\text { United States }\end{array}$ \\
\hline
\end{tabular}




\begin{tabular}{|c|c|c|}
\hline CHEP'89 & 10-14 April 1989 & $\begin{array}{l}\text { Oxford, England, } \\
\text { United Kingdom }\end{array}$ \\
\hline CHEP'90 & 9-13 April 1990 & $\begin{array}{c}\text { Santa Fe, New } \\
\text { Mexico, United States }\end{array}$ \\
\hline CHEP'91 & 11-15 March 1991 & Tsukuba, Japan \\
\hline CHEP'92 & $\begin{array}{c}\text { 21-25 September } \\
1992 \\
\end{array}$ & Annecy, France \\
\hline CHEP'94 & 21-27 April 1994 & $\begin{array}{c}\text { San Francisco, } \\
\text { California, United } \\
\text { States }\end{array}$ \\
\hline$\underline{\text { CHEP'95 }}$ & $\begin{array}{c}\text { 18-22 September } \\
1995 \\
\end{array}$ & Rio de Janeiro, Brazil \\
\hline$\underline{\text { CHEP'97 }}$ & 7-11 April 1997 & Berlin, Germany \\
\hline CHEP'98 & $\begin{array}{c}31 \text { August }-4 \\
\text { September } 1998 \\
\end{array}$ & $\begin{array}{c}\text { Chicago, Illinois, } \\
\text { United States } \\
\end{array}$ \\
\hline CHEP'2000 & 7-11 February 2000 & Padova, Italy \\
\hline$\underline{\text { CHEP'01 }}$ & $\begin{array}{l}\text { 3-7 September } \\
2001\end{array}$ & Beijing, China \\
\hline$\underline{\text { CHEP'03 }}$ & 24-28 March 2003 & $\begin{array}{c}\text { San Diego, California } \\
\text { United States }\end{array}$ \\
\hline CHEP'04 & $\begin{array}{l}27 \text { September - } 1 \\
\text { October } 2004\end{array}$ & $\begin{array}{l}\text { Interlaken, } \\
\text { Switzerland }\end{array}$ \\
\hline$\underline{\text { CHEP'06 }}$ & $\begin{array}{c}\text { 13-17 February } \\
2006\end{array}$ & Mumbai, India \\
\hline$\underline{\text { CHEP'07 }}$ & $\begin{array}{c}\text { 2-7 September } \\
2007\end{array}$ & $\begin{array}{c}\text { Victoria, British } \\
\text { Columbia, Canada }\end{array}$ \\
\hline CHEP'09 & 21-27 March 2009 & $\begin{array}{c}\text { Prague, Czech } \\
\text { Republic }\end{array}$ \\
\hline$\underline{\text { CHEP'10 }}$ & $\begin{array}{c}18-22 \text { October } \\
2010\end{array}$ & Taipei, Taiwan \\
\hline$\underline{\text { CHEP'12 }}$ & 21-25 May 2012 & $\begin{array}{c}\text { New York, New } \\
\text { York, United States }\end{array}$ \\
\hline$\underline{\text { CHEP'13 }}$ & 14-18 October 2013 & $\begin{array}{l}\text { Amsterdam, } \\
\text { Netherlands }\end{array}$ \\
\hline$\underline{\text { CHEP'15 }}$ & 13-17 April 2015 & Okinawa, Japan \\
\hline$\underline{\text { CHEP'16 }}$ & 10-14 October 2016 & $\begin{array}{c}\text { San Francisco, } \\
\text { California, United } \\
\text { States }\end{array}$ \\
\hline
\end{tabular}

\subsection{CHEP 2018 Conference}

The International Conference on Computing in High Energy and Nuclear Physics (CHEP) took place in the National Palace of Culture, Sofia, Bulgaria from 9th to 13th of July 2018 with 575 participants, including 56 students. The conference was organized by the Institute for Advanced Physical Studies, Sofia University, Plovdiv University, New Bulgarian University, Burgas Free University, INRNE-BAS, IICT-BAS and Sofia Municipality. It was hosted in the National Palace of Culture. The National Palace of Culture (NDK), in the heart of Sofia, is the largest multifunctional conference and exhibition centre in South-Eastern Europe. It was opened in 1981 in celebration of Bulgaria's 1300th anniversary. NDK hosts over 300 events per year with one million guests. It is decorated with 80 monumental works of art entwined into the halls and foyers. 
It occupies an area of $123,000 \mathrm{~m} 2$ on eight floors and three underground levels. Additional information can be found on the conference Web page chep2018.org.

\subsection{CHEP 2018 Program}

The program of the CHEP 2018 conference accommodated plenary sessions and 8 parallel tracks. 27 plenary talks were either given by invited speakers or selected and promoted from the abstracts in the different tracks. The main topics of the plenary talks concerned HPC and cloud computing, machine learning in High Energy Physics (HEP), overviews of experiment software for data acquisition, high level triggering, reconstruction and analysis, experience from astro-particle and neutrino physics, as well as broader subjects like multithreading and vectorization in HEP, use of blockchains, quantum computing, software citation mechanisms. Several presentations covered common and widely used tools and packages in HEP such as ROOT, EOS and CVMFS. There was a dedicated presentation on the ways to implement a successful diversity program in the field of HEP and nuclear physics computing. 323 parallel presentations and 188 posters were shown during the 49 parallel and 2 poster sessions. The conference concluded with 8 summary talks from each parallel track, and a forward look to the CHEP 2019 conference in Adelaide, Australia. The subjects and the keywords describing the details of each parallel track are summarised in Table 2.

Table 2. Parallel tracks

\begin{tabular}{|c|c|c|}
\hline & Track & Keywords \\
\hline 1. & Online computing & $\begin{array}{l}\text { Data acquisition (DAQ); High Level Triggers (HLT); trigger } \\
\text { and trigger-less acquisition; data calibration; online } \\
\text { reconstruction; filtering and compression; event building; } \\
\text { configuration and access controls; detector control systems. }\end{array}$ \\
\hline 2. & Offline computing & $\begin{array}{l}\text { Event generation; simulation and reconstruction; detector } \\
\text { geometries; data classification; visualization and data } \\
\text { presentation, outreach. }\end{array}$ \\
\hline 3. & Distributed computing & $\begin{array}{l}\text { Computing models; Grid middleware; monitoring and } \\
\text { accounting frameworks; security models and tools; } \\
\text { distributed workload; high performance computing (HPC) } \\
\text { and supercomputers. }\end{array}$ \\
\hline 4. & Data handling & $\begin{array}{l}\text { Storage management frameworks; data access protocols; } \\
\text { object, metadata and event store systems; databases. }\end{array}$ \\
\hline 5. & Software development & $\begin{array}{l}\text { Software frameworks; software management, building, } \\
\text { testing, quality assurance and distribution; programming } \\
\text { techniques and tools. }\end{array}$ \\
\hline 6. & $\begin{array}{l}\text { Machine learning and } \\
\text { physics analysis }\end{array}$ & $\begin{array}{l}\text { Algorithms for physics object identification; machine } \\
\text { learning systems and tools; data and analysis preservation. }\end{array}$ \\
\hline 7. & $\begin{array}{l}\text { Clouds, virtualization } \\
\text { and containers }\end{array}$ & $\begin{array}{l}\text { Cloud, virtual machines and container technologies; } \\
\text { anything-as-a-service; private and commercial clouds. }\end{array}$ \\
\hline 8 , & Networks and facilities & $\begin{array}{l}\text { LAN and WAN; overlay, private and virtual networks; } \\
\text { monitoring and management tools; computing centre } \\
\text { infrastructure, management and monitoring. }\end{array}$ \\
\hline
\end{tabular}


The slides of the presentations and the PDF files of the posters are available from the Indico Web pages at https://indico.cern.ch/event/587955/timetable.

\section{International Advisory Committee}

The International Advisory Committee (IAC) of the conference was chaired by the three CHEP2018 co-organisers:

Peter Hristov, CERN;

Petya Vasileva, CERN;

Vassil Vassilev, Princeton.

The chairs of the Program Committee (PC) were elected by the IAC and became ex-officio members of the IAC:

Latchezar Betev, CERN, PC Chair;

Alessandra Forti, University of Manchester, Deputy PC Chair;

Maarten Litmaath, CERN, Deputy PC Chair;

Oxana Smirnova, University of Lund, Deputy PC Chair.

The organizers of CHEP2019 became members of the IAC when Adelaide was selected as the next conference lieu:

Paul Jackson, University of Adelaide;

Waseem Kamleh, University of Adelaide.

Table 3. Members of the International Advisory Committee

\begin{tabular}{|l|l|l|}
\hline \multicolumn{1}{|c|}{ Name } & \multicolumn{1}{|c|}{ Affiliation } & Experiment \\
\hline Alessandra Forti & University of Manchester, UK & ATLAS \\
\hline Amber Boehnlein & $\underline{\text { JLAB, Newport News, VA, USA }}$ & \\
\hline Borut Kersevan & $\underline{\text { University of Ljubljana, Slovenia }}$ & ATLAS \\
\hline Daniele Bonacorsi & $\underline{\text { University of Bologna/INFN, Italy }}$ & CMS \\
\hline David Groep & $\underline{\text { NIKHEF, Amsterdam, Netherlands }}$ & LHCb \\
\hline David Malon & $\underline{\text { ANL, Lemont IL, USA }}$ & ATLAS \\
\hline Elizabeth Sexton-Kennedy & $\underline{\text { FNAL, Batavia IL, USA }}$ & CMS \\
\hline Federico Carminati & $\underline{\text { CERN, Geneva, Switzerland }}$ & \\
\hline
\end{tabular}




\begin{tabular}{|c|c|c|}
\hline Gang Chen & 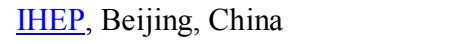 & RE1 \\
\hline Ghita Rahal & $\underline{\mathrm{CC}-\mathrm{IN} 2 \mathrm{P} 3}$, Villeurbanne, France & ATLAS \\
\hline Graeme Stewart & CERN, Geneva, Switzerland & \\
\hline Ian Bird & CERN, Geneva, Switzerland & \\
\hline Jeff Templon & NIKHEF, Amsterdam, Netherlands & \\
\hline Jerome Lauret & BNL, Upton NY, USA & STAR \\
\hline Latchezar Betev & CERN, Geneva, Switzerland & ALICE \\
\hline Maarten Litmaath & $\underline{\text { CERN, Geneva, Switzerland }}$ & \\
\hline Marco Cattaneo & CERN, Geneva, Switzerland & $\mathrm{LHCb}$ \\
\hline Maria Girone & $\underline{\text { CERN, Geneva, Switzerland }}$ & CMS \\
\hline Mohammad Al-Turany & 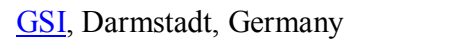 & \\
\hline Niko Neufeld & CERN, Geneva, Switzerland & $\mathrm{LHCb}$ \\
\hline Oxana Smirnova & Lund University, Sweden & ATLAS \\
\hline Patrick Fuhrmann & DESY, Hamburg, Germany & \\
\hline Paul Jackson & University of Adelaide, Australia & \\
\hline Pere Mato Vila & CERN, Geneva, Switzerland & \\
\hline Peter Clarke & University of Edinburgh, UK & $\mathrm{LHCb}$ \\
\hline Peter Elmer & Princeton University, NJ, USA & CMS \\
\hline Peter Hristov & CERN, Geneva, Switzerland & ALICE \\
\hline Petya Vasileva & CERN, Geneva, Switzerland & ATLAS \\
\hline
\end{tabular}




\begin{tabular}{|c|c|c|}
\hline Predrag Buncic & $\underline{\text { CERN, Geneva, Switzerland }}$ & ALICE \\
\hline Reda Tafirout & 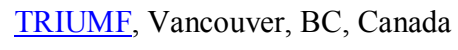 & ATLAS \\
\hline Richard Mount & 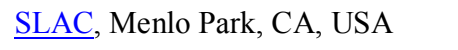 & ATLAS \\
\hline Simon Lin & Academia Sinica, Taipei, Taiwan & \\
\hline Simone Campana & CERN, Geneva, Switzerland & \\
\hline Stefan Roiser & $\underline{\text { CERN, Geneva, Switzerland }}$ & $\mathrm{LHCb}$ \\
\hline Takanori Hara & 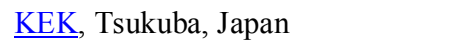 & BELLE II \\
\hline Thomas Kuhr & $\underline{\text { LMU, Munich, Germany }}$ & BELLE II \\
\hline Thorsten Kollegger & GSI, Darmstadt, Germany & ALICE \\
\hline Tobias Stockmanns & $\underline{\text { IKP }}$, Juelich, Germany & PANDA \\
\hline Tommaso Boccali & $\underline{\text { INFN, }}$ Pisa, Italy & CMS \\
\hline Tomoaki Nakamura & 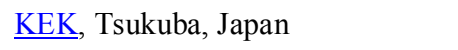 & \\
\hline Vassil Vassilev & 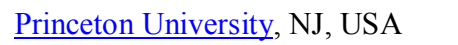 & CMS \\
\hline Vladimir Korenkov & $\underline{\text { JINR, Dubna, Russia }}$ & \\
\hline Waseem Kamleh & 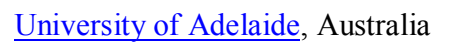 & \\
\hline
\end{tabular}

The IAC had 25 meetings. It elected the chair and deputy chairs of the Program committee, prepared the long list of the track conveners and elected them as members of the Program Committee. Together with the PC, the IAC defined the list of parallel tracks and approved the associated keywords. The details of the program and the distribution of the time slots were prepared by the PC and discussed by the IAC considering the number of submitted abstracts per track. The IAC proposed the invited speakers of CHEP 2018 and selected the list of plenary talks based on the suggested abstracts. The IAC also voted on the proposals for the next CHEP lieu and selected Adelaide, Australia. CHEP 2019 will take place from the 4th to 8th of November 2019. More information can be found on the conference Web site chep2019.org. 


\section{Program Committee}

The members of the Program Committee (PC) were nominated by the IAC and the final composition was approved seeking gender, geographical, experiment and institutional balance. The PC members were responsible for the selection of abstracts, allocation of oral and poster slots, and served as track conveners during the conference. In addition, they organised the editorial reviews of the CHEP 2018 proceedings.

Table 4. List of conveners per track.

\begin{tabular}{|c|c|c|}
\hline Name & Affiliation & $\begin{array}{c}\text { Experime } \\
\text { nt }\end{array}$ \\
\hline \multicolumn{3}{|c|}{ Track 1 Online Computing } \\
\hline Adriana Telesca & CERN, Geneva, Switzerland & ALICE \\
\hline Catrin Bernius & $\underline{\text { SLAC, }}$ Menlo Park, CA, USA & ATLAS \\
\hline Clara Gaspar & 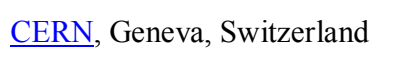 & $\mathrm{LHCb}$ \\
\hline Ryosuke Itoh & $\underline{\text { KEK, }}$ Tsukuba, Japan & BELLE II \\
\hline \multicolumn{3}{|c|}{ Track 2 Offline Computing } \\
\hline Daniel Elvira & FNAL, Batavia IL, USA & CMS \\
\hline Gene Van Buren & 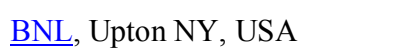 & STAR \\
\hline Heather Grey & $\underline{\mathrm{LBL}}$, Berkeley CA, USA & ATLAS \\
\hline Lucia Grillo & $\underline{\text { INFN, }}$ Milano-Bicocca, Italy & $\mathrm{LHCb}$ \\
\hline \multicolumn{3}{|c|}{ Track 3 Distributed computing } \\
\hline David Cameron & University of Oslo, Norway & ATLAS \\
\hline Hannah Short & $\underline{\text { CERN, Geneva, Switzerland }}$ & - \\
\hline Julia Andreeva & $\underline{\text { CERN, Geneva, Switzerland }}$ & - \\
\hline Ikuo Ueda & $\underline{\text { KEK}}$, Tsukuba, Japan & BELLE II \\
\hline
\end{tabular}




\begin{tabular}{|c|c|c|}
\hline \multicolumn{3}{|c|}{ Track 4 Data handling } \\
\hline Costin Grigoras & $\underline{\text { CERN, Geneva, Switzerland }}$ & ALICE \\
\hline Elizabeth Gallas & University of Oxford, UK & ATLAS \\
\hline Maria Arsuaga Rios & CERN, Geneva, Switzerland & - \\
\hline Tigran Mkrtchyan & DESY, Hamburg, Germany & - \\
\hline \multicolumn{3}{|c|}{ Track 5 Software development } \\
\hline Barthélémy von Haller & CERN, Geneva, Switzerland & ALICE \\
\hline Maiken Pedersen & $\underline{\text { University of Oslo, Norway }}$ & ATLAS \\
\hline Philippe Canal & FNAL, Batavia IL, USA & CMS \\
\hline Patricia Mendez Lorenzo & $\underline{\text { CERN, Geneva, Switzerland }}$ & - \\
\hline \multicolumn{3}{|c|}{ Track 6 Machine learning and physics analysis } \\
\hline Andrea Rizzi & $\underline{\text { INFN, }}$ Pisa, Italy & CMS \\
\hline Michela Paganini & 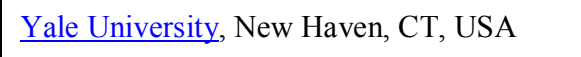 & ATLAS \\
\hline Sergei Gleyzer & University of Florida, Gainesville, FL, USA & CMS \\
\hline Sofia Vallecorsa & 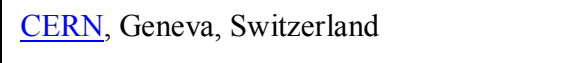 & - \\
\hline \multicolumn{3}{|c|}{ Track 7 Clouds, virtualization and containers } \\
\hline Andrew $\mathrm{McNab}$ & $\underline{\text { University of Manchester, UK }}$ & $\mathrm{LHCb}$ \\
\hline Dave Dykstra & 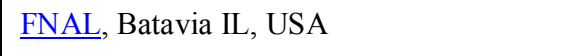 & CMS \\
\hline Fabio Hernandez & 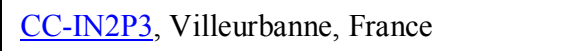 & - \\
\hline Martin Sevior & University of Melbourne, Australia & BELLE II \\
\hline
\end{tabular}




\begin{tabular}{|l|l|l|}
\hline \multicolumn{2}{|c|}{ Track 8 Networks and facilities } & CMS \\
\hline Oksana Shadura & University of Nebraska, USA & CMS \\
\hline Pepe Flix & $\underline{\text { PIC, Barcelona, Spain }}$ & - \\
\hline Sang-Un Ahn & $\underline{\text { KISTI, Daejeon, Korea }}$ & ATLAS \\
\hline Wei Yang & $\underline{\text { SLAC, Menlo Park, CA, USA }}$ \\
\hline
\end{tabular}

\section{Local Organizing Committee}

The conference chairs are very grateful to the members of the local organising committee, whose precious help made the conference a resounding success: Alexander Penev, PU; Anna Yaneva, SU \& CERN; Desislava Nikolova, NDK; Evelina Ananieva, MFA; Elitsa Ivanova; Gancho Dimitrov, CERN; Ivelina Todorova, PU; Martin Vasilev, PU; Milena Veneva, FMI - SU; Stoyan Mishev, IAPS; Todor Ivanov, SU \& CERN.

Special thanks to the representatives of the institutions supporting CHEP 2018: Daniela Orozova, BFU; Galya Hristozova, BFU; Georgi Tekev NBU; Leandar Litov, SU; Miroslav Borshosh, NDK; Nevena Ilieva, IICT - BAS; Plamen Iaydjiev, INRNE - BAS, Todor Tchobanov, SM; Tzveta Apostolova, IAPS \& BAS; Venelin Kozhuharov, SU.

\section{Sponsors}

We thank the CHEP 2018 sponsors for crucial contributions to the conference success:

- Platinum sponsors

○ RHEA Group (www.rheagroup.com)

- T-Systems (www.t-systems.com)

- Silver sponsors

○ Intel ( $\underline{\text { www.intel.com }})$

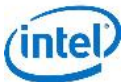

- Chaos Group (www.chaosgroup.com)

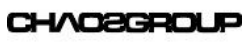

- Bulgarian fund for scientific research,

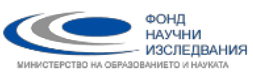
grant DPMNF01/1 (www.fni.bg) 


\section{Acknowledgements}

The success of the CHEP 2018 conference would not have been possible without the help and support from the conference secretariat: Anna Yaneva, Elitsa Ivanova, Evelina Ananieva, and Mariana Shopova, to whom we express our gratitude. We are very thankful to Milena Veneva for the organisation of the microphone service, and to the students who volunteered to participate as microphone runners. Our appreciation also goes to Martin Vasilev for the excellent support of the conference Web page (chep2018.org).

The conference organisers would like to thank very much the NDK staff and Hilton catering for their excellent day-by-day work, support and help. We express special thanks to the Military Club - Sofia for the organisation of the welcome party, to Hotel Marinela Sofia and Joker Media for the conference dinner, to "365 Association" for the organised tour of Sofia, to Sofia Municipality for the transportation cards, to Force Delta for the site security, and to Tokuda Hospital - Sofia for the medical assistance. 